\title{
EL MANUSCRITO DE JUAN MARTÍN, «EL EMPECINADO». DOS VERSIONES PARA DEFINIR AL HÉROE
}

PILAR EsTERÁN

Universidad de Zaragoza

«He aquí un gato que quiso zapatos»(Gerona).

\section{FICHA DESCRIPTIVA DEL MANUSCRITO}

Se trata de un manuscrito autógrafo de Galdós conservado en la Biblioteca Nacional de Madrid con la signatura: Ms. 21.753.

Se compone de 475 cuartillas sueltas y escritas apaisadas.

El ms. conserva todos los folios numerados del 1 al 469.

En este ms. existen dos folios sucesivos distintos numerados como f. 430 y f. 430 respectivamente.

Las medidas de todas las cuartillas son las habituales en los mss. de Galdós: $21,5 \times 16 \mathrm{~cm}$.

La tinta empleada en todos los folios es de color negro.

Las cuartillas están numeradas en el extremo superior izquierdo. El desajuste entre el número real de folios que integran el manuscrito, y la numeración asignada por Galdós se explica si tomamos en consideración que hay cuartillas cuyos números tienen, en otros folios, continuación señalada con los mismos guarismos, a los que se les añade un número fraccionario u ordinal.

Los folios cuya numeración tiene continuación en otras cuartillas son:
f. $31 / 2$
f. $391 / 2$
f. $<110>/ 1091 / 2 /$
f. $<147><148>/ 147 \quad 1 / 2 /$
f. $4081 / 2$ 
Los folios desechados, (vueltos), del ms. de Juan Martín, «El Empecinado» corresponden a los siguientes rectos del mismo ms.:

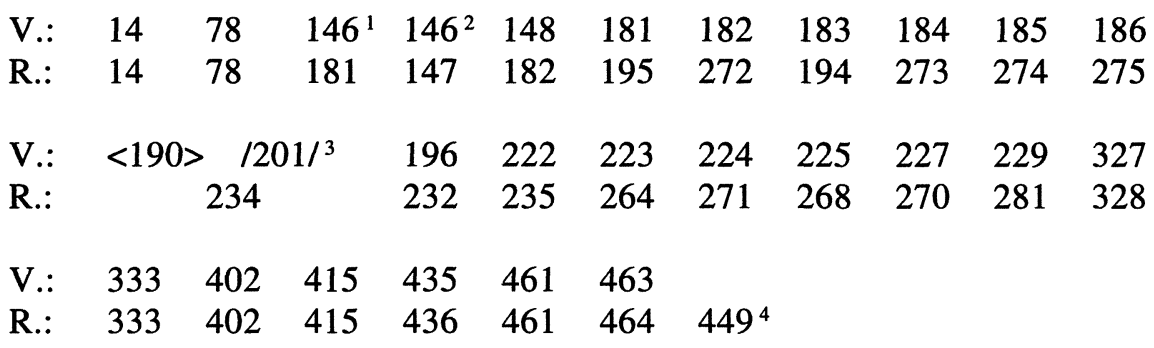

\section{ANÁLISIS DEL PROCESO DE REDACCIÓN DEL MANUSCRITO}

El ms. 21.753, correspondiente al noveno episodio de la primera serie de Episodios nacionales de Benito Pérez Galdós titulado Juan Martín, «El Empecinado», presenta un total de veintisiete vueltos tachados cuyas carillas han sido aprovechadas para la escritura en mayor o menor medida. De estos veintisiete vueltos, en veintiséis de ellos podemos leer textos cuyos contenidos remiten a la narración de «El Empecinado». Es decir, en el ms. 21.753 existen veintiséis vueltos que son fragmentos desechados, en uno u otro momento, de la corriente narrativa de «El Empecinado». A estos veintiséis reversos desechados habría que añadir el f. $<349>$ d /358/, que no se trata propiamente de un vuelto desechado, sino de la parte superior tachada de un anverso que Galdós numeró inicialmente como f. <349> y que, después de desestimado, decidió aprovechar la mayor parte de la superficie de dicha cuartilla, aún en blanco, para redactar el actual f. 1358/. Así pues, el f. $<349>$ d /358/ puede leerse, no en el reverso de alguna cuartilla válida del ms., sino en la parte superior del anverso del actual f. /358/. Por lo que respecta al vuelto que hace el número vigésimo séptimo de los escritos, no aparece en él discurso gráfico, tan sólo hallamos unas cuantas operaciones aritméticas, sumas y productos, ajenas al relato.

Como última peculiaridad del ms. 21.753 cabe anotar que hallamos entre sus cuartillas una de dimensiones un poco más pequeñas de las habituales: $21 \times 13,4 \mathrm{~cm}$. Está escrita en posición vertical y recoge una nota enviada

\footnotetext{
1 Comienzo de línea: «en la sierra desbaratados por Mazuquelli.»

2 Comienzo de línea: «mismo Daroca. Refugiados alli los restos»

3 Para una correcta comprensión de todo lo relativo a la transcripción del ms., véanse los signos de lección definidos en el Apéndice documental.

${ }_{4}$ En el reverso del actual f. 449 hay unas cuantas operaciones aritméticas: sumas y productos.
} 
por uno de sus impresores a don Benito ${ }^{5}$. Dicha nota no corresponde al reverso de ningún folio válido del ms., sino que se encuentra en una cuartilla aparte y está escrita con tinta de color sepia.

De modo semejante a lo ocurrido con otros episodios de la primera serie $^{6}$, la composición de «El Empecinado» exigió también de Galdós la redacción de dos versiones que podemos denominar Alpha y Beta respectivamente, siguiendo con ello la tradición crítica galdosiana ${ }^{7}$.

Sr. Galdós: tenemos preparado el
pliego 15 para empezar mañana lunes;
de modo q los pliegos 16 y 17 nos
hacen hacen [sic] falta tambien por la ma
ñana. Si sale Vd. esta tarde y
y [sic] puede dejárselos ya corregidos al
Sr. Cámara, seria lo mejor; pero
si no puede Vd. dejárselos, en ese caso
ira Francisco á recogerlos á eso de las
diez ó un poco antes. El pliego
18 y las 4 págs. del 19 puedo esperar-
los hasta por la tarde
Suyo

6 Un estudio pormenorizado del proceso compositivo de cada uno de los diez mss. que integran la primera serie de Episodios puede consultarse en mi artículo: «Los mss. de la primera serie de Episodios nacionales. Hipótesis interpretativa del proceso de redacción», Anales Galdosianos, XXXIV, 1999, pp. 13-30.

7 Entre los principales estudios de crítica textual aplicados a los mss. galdosianos son referencia inexcusable: Matilde L. Boo, El manuscrito de "La de San Quintín» de Benito Pérez Galdós, Anales Galdosianos, Anejo 1986; Rodolfo CARDONA, «El manuscrito de Doña Perfecta: una descripción preliminar», Anales Galdosianos, XI, 1976, pp. 9-13; Beatriz ENTENZA DE SOLARE, «Sobre el manuscrito de Marianela», Filología, XIX, 1982-84, pp. 131-134; IDEM, «Sobre los manuscritos de La incógnita y Realidad», Romanische Forschungen, 96, 1984, pp. 430-435; IDEM, «Manuscritos galdosianos», en Actas del III Congreso Internacional de Estudios Galdosianos, Las Palmas, Cabildo Insular de Gran Canaria, 1989, vol. I, pp. 149-161; Pilar ESTERÁN ABAD, «La Fontana de Oro: tres desenlaces para una novela», en Actas del Quinto Congreso Internacional de Estudios Galdosianos, Las Palmas, Cabildo Insular, 1995, vol. I, pp. 77-87; IDEM, «Zaragoza» de Galdós. Edición y estudio críticos, Zaragoza, Institución «Fernando el Católico» (en prensa); IDEM, La primera serie de "Episodios nacionales». Estudio críticoliterario del proceso de redacción, Madrid, F.U.E. (en prensa); Clara Eugenia Hernández CABrera, ed., Benito PÉrez Galdós, El Abuelo, Las Palmas, Cabildo Insular de Gran Canaria, 1993; Martha G. KROW-LUCAL, «The Evolution of Encarnación Guillén in La desheredada», Anales Galdosianos, XII, 1977, pp. 21-29; Mercedes LÓPEZ-BARALT, La gestación de "Fortunata y Jacinta»: Galdós y la novela como reescritura, Río Piedras, Ediciones Huracán, 1992; Ela M. ${ }^{a}$ MARTÍNEZ UMPIÉRREZ, «Los manuscritos de Realidad», en Julián Ávila AREllaNo ed., Galdós. Centenario de «Fortunata y Jacinta» (1887-1987). Actas, Madrid, Universidad Complutense, Facultad de Ciencias de la Información, 1989, pp. 51-59; Walter T. PATTISON, Benito Pérez Galdós. Etapas preliminares de «Gloria», Barcelona, Puvill, 1979; Geoffrey RIBBANS, «La personalidad de Maxi Rubín según el manuscrito de Fortunata y Jacinta», en Julián 
El estudio de este ms. permite constatar que en «El Empecinado» el novelista suspendió la narración de la que podríamos denominar versión Alpha cuando llevaba compuestas unas 229 cuartillas. En consecuencia, en este ms. el desfase entre el número de folios de Alpha, el f. $229 \mathrm{~d}$ es el último numerado, y el número de folios de Beta, el f. 469 es el último numerado, resulta muy relevante. Y lleva consigo aparejado que la versión Alpha suspenda su composición cuando apenas hemos sobrepasado el ecuador de la trama argumental del episodio. Sin que en esta ocasión parezca existir, al menos no se ha conservado, ninguna cuartilla sintética que, a modo de guión, esboce los futuros derroteros de la peripecia novelesca.

Así pues, y en tanto no aparezcan nuevos folios desechados, podemos concluir que Galdós continuó ininterrumpidamente la primera redacción de «El Empecinado» hasta llegar al f. 229, instante crítico de la narración en que hizo crisis esta versión inicial. A partir de ese momento el novelista procede a la revisión sistemática de las cuartillas compuestas y se inicia el proceso de transformación de Alpha en Beta.

En absoluto puede hablarse de estilo telegráfico para definir alguna de

Ávila Arellano ed., Galdós. Centenario de «Fortunata y Jacinta» (1887-1987). Actas, Madrid, Universidad Complutense, Facultad de Ciencias de la Información, 1989, pp. 591-597; IDEM, «Doña Perfecta: Yet Another Ending», Modern Language Notes, 105, n. 2 2, 1990, pp. 203-225; IDEM, «The Making of a Minor Character: Galdós's Plácido Estupiñá», Symposium, XLVI, 1992, pp. 147-157; IDEM, Conflicts and Conciliations: The Evolution of Galdós's «Fortunata y Jacinta», Indiana, Purdue University Press, 1997; Michael ALLEN SCHNEPF, «A Guide to the Manuscripts of Galdós's Second Series of Episodios nacionales», Anales Galdosianos, XXVI, 1991, pp. 35-42; IDEM, «From the Manuscripts of Galdós's Second Series of Episodios nacionales: On the Creation of Juan Bragas de Pipaón», Crítica Hispánica, XIII, 1991, pp. 21-29; IDEM, «Galdós's El doctor Centeno Manuscript: Pedro Polo and Other Curiosities», Romance Quarterly, 41, 1994, pp. 36-42; IDEM, «Galdós's La desheredada Manuscript: José Relimpio y Sastre», Hispanófila, 1990, n. ${ }^{\circ}$ 100, pp. 7-14; IDEM, «Galdós's Tristana Manuscript: Don Lope Garrido», Romance Notes, XXXI, n. ${ }^{\circ} 1,1990$, pp. 11-18; IDEM, «Galdós's La desheredada Manuscript: A note on the Creation of Isidora Rufete», Romance Notes, XXXI, n. ${ }^{\circ}$ 3, 1991, pp. 245-250; IDEM, «(Re)discovering Galdós's Casandra Manuscript», Anales Galdosianos, XXIX-XXX, 1994-1995, pp. 121-127; IDEM, «The Manuscript of Galdós's Tormento», Anales Galdosianos, XXVI, 1991, pp. 43-49; Jonh H. SINNIGEN, «Tristana: la tentación del melodrama», en Actas del X Congreso de la Asociación Internacional de Hispanistas, Barcelona, 21-26 de agosto de 1989, Antonio Vilanova ed., Barcelona, PPU, 1992, vol. II, pp. 1485-1490; Alan E. SMITH, ed., Benito PÉREZ GALDós, [Rosalía] Madrid, Cátedra, 1983; Dolores Troncoso, ed., Benito PÉrEZ Galdós, Trafalgar. La corte de Carlos IV, Barcelona, Crítica, 1995; Robert, J. WEBER, The «Miau» Manuscript of Pérez Galdós: A Critical Study, Berkeley-Los Ángeles, University of California Press, 1964; James Whiston, The Early Stages of Composition of Galdós' "Lo Prohibido», London, Tamesis Books Limited, 1983; IDEM, «The Manuscript of Galdós' Un voluntario realista», Kentucky Romance Quarterly, XXXV, 1987, pp. 351-360; IDEM, «Historia y proceso creativo en el Episodio nacional, Un voluntario realista», en Actas del III Congreso Internacional de Estudios Galdosianos, Las Palmas, Cabildo Insular de Gran Canaria, 1989, vol. II, pp. 337-346. 
sus partes, o la totalidad en general, de esta primera versión. El texto de Alpha se halla redactado de forma completa y minuciosa. Sin embargo, Alpha sí ha de ser definida como una redacción estimada provisional por el escritor, y sobre la cual nuestro autor en algún momento debía volver, al menos para completar aquellas secuencias que había dejado muy escuetamente indicadas con sendas notas aclaratorias para sí mismo. Independientemente de que, además, pensase o no modificar el texto ya escrito. Dichos guiones sintéticos construidos con unas pocas palabras clave pueden leerse en el f. $223 d$ y el f. $227 d^{8}$.

Por lo que se refiere al proceso de transformación de Alpha en Beta, Galdós se ajustó a lo que, según hemos podido comprobar, son sus técnicas habituales en los mss. con dos redacciones. Los primeros folios de Alpha pasaron prácticamente tal cual de una a otra versión. Y por lo que se refiere a las restantes cuartillas de. Alpha, unas fueron desechadas y reescritas de nuevo, mientras que otras también pasaron de la primera redacción a la segunda sin alterar su contenido y mediante el recurso elemental de corregir su numeración para incardinarlas en la nueva corriente textual de Beta.

En general, podemos afirmar que los ciento ochenta folios primeros de Alpha pasaron a Beta prácticamente en bloque y con alteraciones muy contadas en las que no me detendré. Las diferencias sustanciales entre una y otra versión se desencadenan a partir del primitivo f. 181d. Galdós ha desechado una secuencia de antiguos folios de Alpha que va del f. 181d al f. 186d, ambos inclusive, y los ha reescrito ampliados en los actuales f. 181 al f. 197, ambos inclusive, de Beta. El cambio es fundamental para el significado trascendente del episodio. Se trata de la escena en la que se narra el enfrentamiento entre don Juan Martín y don Saturnino Albuin (cap. XI, p. 79-86) ${ }^{9}$. Es comprensible que Galdós no quedase plenamente satisfecho con la primera redacción, y compuso una segunda, más extensa, que le permitió perfilar con mejor tino los caracteres de ambos contrincantes y que, sobre todo, contribuye a la exaltación personal de la figura de «el Empecinado». Don Juan Martín pasa de mostrarse arrebatado y violento, casi en los mismos términos que el Manco, en la primera versión, a conducirse en la segunda redacción como un jefe autoritario pero generoso y al que sólo acaba por desencajar la traición manifiesta de sus subordinados.

Dado que la secuencia inicial iba del f. 181d al f. 186d, en tanto que la secuencia final abarca del nuevo f. 181 al nuevo f. 197, resulta obvio

8 Consúltense las transcripciones de estos folios desechados que proporciono en el Apéndice documental.

9 Cito por la edición de Alianza, 1984. Después de las sucesivas colaciones realizadas para preparar la edición crítica de Zaragoza, entiendo que Alianza ofrece, para cualquier clase de estudio crítico, el texto más fiable de todas las ediciones comerciales existentes. 
que se ha producido en Beta una ampliación notable de la materia narrativa. Ello obligó al novelista a corregir la numeración de todos aquellos folios de Alpha, a partir del antiguo f. $<187>$, que pensó seguir aprovechando en Beta. De esta manera encontramos una serie de folios de Alpha, desde el antiguo f. $<187>$, actual f. /198/, hasta el antiguo f. $<221>$, actual f. $/ 231 /$, en la que todas las cuartillas sin excepción presentan corregida su primitiva numeración y sustituida por una nueva que es la que les corresponde según la definitiva ordenación de Beta.

En esta serie de cuartillas de Alpha reenumeradas al pasar a Beta la única excepción la constituye el actual f. 201, el cual no ofrece una numeración previa corregida porque dicho f. 201 ha sido reescrito sobre la base de un anterior folio de Alpha, reaprovechado en Beta, y finalmente desechado: el f. <190>/201/d. Éste último, efectivamente, sí presenta una numeración tachada y sustituida por otra.

Como puede apreciarse, el cambio de numeración en esta secuencia de folios de Alpha trasladados a Beta supone un incremento constante para cada cuartilla de once unidades sobre la numeración previa. Recordemos que once cuartillas era exactamente el aumento de extensión que había experimentado la narración del enfrentamiento entre Albuin y «el Empecinado» en la versión Beta. Este incremento de once unidades sobre el referente numérico anterior se mantiene hasta el f. $<195>/ 206 /$. Pero mientras reordenaba la numeración de esta larguísima secuencia de Alpha reaprovechada en Beta, el novelista optó por suprimir una carta intrascendente de la condesa a Araceli que aparecía en el antiguo f. 196d de la primera versión. De ahí que, a partir del folio siguiente, el f. $<197><206>$ /207/, el incremento constante en la numeración de cada cuartilla sobre el referente numérico previo sea de diez unidades.

La última serie de folios conservados de Alpha iría del antiguo f. $222 \mathrm{~d}$ al antiguo f. 229d, ambos inclusive. De esta secuencia se han perdido un supuesto $*$ f. $226 \mathrm{~d}$ y un supuesto $* \mathrm{f}$. $228 \mathrm{~d}$. La serie entera de Alpha ha sido desechada y su contenido reescrito en un sentido amplio en los actuales f. 232 al f. 274, ambos inclusive, de Beta (caps. XIV-XV-XVI-XVII, pp. 99-115). Para entender mejor esta ampliación asombrosa de la materia narrativa conviene recordar que entre los folios tachados había notas sintéticas alusivas a peripecias de la narración que ahora en Beta son desarrolladas plenamente. Sea como fuere, desde luego no queda duda de que los últimos comentarios de Santorcaz que aparecían en el primitivo f. 229d han sido reiterados en los nuevos f. 273 y f. 274 de Beta.

A partir del f. 275 y hasta el f. 469, el último de este ms., todas las cuartillas han sido compuestas ex novo para Beta, sin que hasta la fecha podamos documentar la más ligera referencia en Alpha para esta segunda mitad del episodio.

Resumiendo pues, podemos decir que del total contabilizado de vein- 
tiséis vueltos desechados cuyos contenidos remitían a «El Empecinado», trece de ellos eran antiguos folios de Alpha, válidos en esta primera redacción, y que fueron desestimados en el momento de proceder a la transformación de Alpha en Beta. Se trata, como era lógico esperar, de cuartillas redactadas completas y son: f. 181d-f. 182d-f. 183d-f. 184d-f. 185d-f. 186d, f. 196d, f. 222d-f. 223d-f. 224d-f. 225d-f. 227d y f. 229d.

Por lo que hace a la segunda mitad del texto del episodio, que ya he indicado es creación exclusiva de Beta, hallamos un total de siete cuartillas tachadas cuya numeración y contenidos remiten a esta segunda mitad del texto. Son las siguientes: f. 327d, f. 333d, f. 402d, f. 415d, f. 435d, f. $461 \mathrm{~d}$ y f. $463 \mathrm{~d}$. Todas ellas fueron desechadas en el mismo instante de su composición, es decir, mientras Galdós acababa de redactar su definitiva versión Beta. Es por ello por lo que se trata de folios en los que el novelista sólo ha llegado a anotar unas pocas líneas antes de desecharlas y comenzar la redacción de un nuevo folio con la misma numeración que el suprimido. Entre los vueltos tachados de Beta únicamente hay una cuartilla, el f. 402, que aparece redactada completa. No obstante, también ésta fue desestimada en el momento de su escritura y el novelista inició la composición del definitivo f. 402 porque le interesaba que la corriente narrativa discurriese por otros derroteros. Un folio desechado de Beta, y tachado en el mismo instante de su composición, es también el f. <349>d $1358 /$, aunque en esta ocasión las pocas líneas suprimidas, correspondientes a un anterior f. $<349>$ d, se leen, no en un vuelto, sino en la mitad superior tachada del anverso del actual f. 1358/.

\section{ESTRATEGIAS NARRATIVAS EN LA COMPOSICIÓN DE JUAN MARTÍN, «EL EMPECINADO»}

Ya ha quedado apuntado que el ms. de este episodio presentaba dos redacciones sucesivas Alpha y Beta. Del análisis de las mismas se deduce que, durante la elaboración de la versión primitiva, el novelista atendió fundamentalmente al desarrollo de la trama novelesca propia de esta novela, es decir, los conflictos intestinos desatados en la partida del Empecinado. En tanto que, al componer el texto definitivo, el novelista buscó, no sólo concluir la trama argumental iniciada en Alpha, sino también anudar el hilo folletinesco que había de vincular a este noveno episodio con el conjunto de la primera serie. Me refiero a la aventura sentimental que envuelve a Gabriel Araceli, a su amada Inés, a la condesa Amaranta y a don Luis de Santorcaz

Prácticamente, los primeros 180 folios de Alpha pasan sin alteraciones a Beta. En esas iniciales 180 cuartillas tenemos completamente perfilado el conflicto argumental que se desarrolla en esta novela. 
Desde el principio, el novelista ha querido dejar constancia de los males que las guerrillas acarreaban a la nación. Por un lado, la adhesión de los hombres a las partidas implicaba el abandono de las tareas productivas y la paralización económica del país (cap. I). Por otro, eran constantes los desafueros cometidos por los guerrilleros en aras de la defensa de la patria (cap. X). A Galdós le horripila el carácter sanguinario de los jefes de las partidas, los cuales expoliaban sin piedad los mismos pueblos que liberaban de franceses. La crítica es tan acerba, que el episodio se abre con la escena de unas mujeres de Sacedón que maldicen igualmente a franceses y guerrilleros por saquear sin compasión sus menguadas despensas.

Dendle ${ }^{10}$ insistió en la resistencia de don Benito a incluir en el ciclo de la Guerra de la Independencia un capítulo dedicado a las guerrillas. En las páginas de este episodio el escritor vierte sin pudor un juicio histórico sobre el significado de las guerrillas y su trascendencia posterior (cap. V, pp. 39-42). El texto está ya compuesto en Alpha y pasa sin alteraciones a Beta. Galdós entiende que estas partidas de paisanos armados garantizaron la unidad nacional, mas pusieron en evidencia la desarticulación del Estado y supusieron una lacra para la organización política de los años venideros. En unos párrafos de lucidez impresionante, el escritor enlaza los sucesos pasados con los presentes y con la esencia díscola del pueblo español, capaz como ningún otro de articularse en una fuerza organizada que ponga en jaque la autoridad del Estado ${ }^{11}$. Esta larga digresión ocupa todo el cap. V y viene a confirmar la idea apuntada por Dendle. Don Benito declara explícitamente que no ha compuesto este episodio para relatar las glorias de las partidas, sino para

enaltecer las hazañas de un guerrillero insigne, que siempre se condujo movido por nobles impulsos, y fue desinteresado, generoso, leal y no tuvo parentela moral con facciosos, ni matuteros, ni rufianes, aunque sin quererlo, y con fin muy laudable, cual era el limpiar a España de franceses, enseñó a aquéllos el oficio.» (p. 40).

Esta novela ha sido escrita para la mayor gloria de Juan Martín, «el Empecinado» ${ }^{12}$. Un guerrillero cuya trayectoria personal de liberal a ultranza y mártir de la represión fernandina le habían granjeado la estima de nuestro novelista. Existe una escena emotiva en la que el guerrillero expresa

10 Brian J. DENDLE, «Una nota sobre la génesis de los Episodios nacionales», en Galdós y la novela histórica, Ottawa, Dovehouse Editions, 1992, pp. 35-40.

11 Así lo vio el maestro Joaquín CASALDUERo, Vida y obra de Galdós (1843-1920), Madrid, Gredos, 1974, p. 49.

${ }_{12}$ Véanse al respecto dos artículos de Gabriel H. LOVETT: «Some Observations on Galdós' Juan Martín, el Empecinado», Modern Language Notes, 84, 1969, pp. 196-207; y «Two Views of Guerrilla Warfare: Galdós' Juan Martín, el Empecinado and Baroja's El escuadron del brigante», Revista de Estudios Hispánicos, VI, 1972, pp. 335-344. 
con candidez su confianza en el nuevo orden constitucional que se va a instaurar en España, prometiendo por su parte ayudar a sostenerlo, si el rey Fernando reclama sus servicios (cap. VI, p. 46).

El héroe necesitaba unos antagonistas que quedan encarnados en las figuras de don Saturnino Albuin y mosén Antón Trijueque ${ }^{13}$. Ambas figuras aparecen perfiladas en la versión primitiva sin ningún tipo de vacilación. Albuin personifica la codicia y el sacerdote la envidia cainita unida al orgullo. Uno y otro fraguan la destrucción de una partida que se había mostrado invulnerable a los ataques franceses.

En la primera redacción ya estaba prevista la defección de los dos lugartenientes. De hecho, la secuencia crucial de todo el relato es justamente la que narra la insubordinación de Albuin, ya que dicha escena resulta determinante en la configuración de la personalidad del Empecinado y en la significación última que Galdós atribuye a esta figura histórica, a la cual dedica su episodio. El enfrentamiento entre don Saturnino y Juan Martín por los dineros que el primero ha robado al tío Garrapinillos al saquear Calcena es la primera escena importante afectada en el proceso de transformación de Alpha en Beta. El novelista ha reescrito completa esta secuencia para ampliarla y mejorarla.

(VARIANTE 1) Estamos en el cap. XI (pp. 79-86), f. 181d-f. 182d-f. 183d-f. 184d-f. 185d-f. 186d: han sido reescritos en los actuales f. 181 al f. 197, ambos inclusive. Se trata del enfrentamiento entre don Juan Martín y don Saturnino Albuin. Es, sin margen de duda, la escena fundamental en el entramado de la ficción novelesca.

La primera redacción no establecía, ni mucho menos, la diferente catadura moral de sus protagonistas: Albuin y Juan Martín. En los folios tachados el héroe reclamaba a su subordinado el dinero robado a los campesinos. La negativa de Albuin a devolverlo cegaba al Empecinado, quien, en un arrebato de ira y sin calcular las consecuencias de su decisión, condenaba al Manco a morir arcabuceado. De igual manera, y sin justificación aparente, don Juan decidía luego indultar al condenado con completo menoscabo de su autoridad, ya que, tal como se sucedían los hechos, cobraba fuerza la impresión de que eran ciertas las palabras finales de Albuin, que despreciaba el gesto de su jefe porque no advertía en él generosidad sino miedo.

Si algo ponía de manifiesto esta primera redacción, era el carácter arrebatado de don Juan Martín, junto con una pérdida completa de la cualidad fundamental que siempre ha de asistir a cualquier héroe: la serenidad de

13 Para el análisis de los personajes conviene revisar: Ward H. DENNIS, Pérez Galdós: a Study in Characterization. «Episodios nacionales» First Series, Madrid, Sucesores de Rivadeneyra, 1968; Nigel GLENDINNING, «Psichology an Politics in the First Series of the Episodios nacionales» en J. E. Varey ed., Galdós Studies, London, Tamesis Books, 1970, pp. 36-61 y Brian J. DENDLE, Galdós. The Early Historical Novels, Missouri, University of Missouri Press, 1986, pp. 76-79. 
juicio ante cualquier circunstancia. Don Vicente Sardina era el único personaje que no veía ofuscada en ningún momento su lucidez mental, atisbando inmediatamente el conflicto intestino que podía desatar la decisión impremeditada de su jefe.

Muy al contrario, la segunda redacción facilitará un desarrollo más ejemplar de la personalidad del Empecinado y también pondrá de relieve la ruindad moral de Albuin. Cuando éste se niega a dar el dinero reclamado, don Juan, siempre generoso, decide atarlo y hacerlo prisionero para imponer su autoridad en la partida; pero nunca piensa en fusilarlo. Asistimos al forcejeo entre los dos hombres, hasta que el Empecinado consigue amarrarlo. El Manco, cual perro rabioso, muerde la mano de su apresador $\mathrm{y}$, una vez libre, comete la villanía imperdonable de concitar a las tropas a la sublevación. Corren en su ayuda sus incondicionales. Ello da pie al novelista para poner de relieve la indisciplina y bajeda de miras de la mayoría de los integrantes de aquellas partidas, pero también ilustra el carácter heroico del Empecinado, que les hace frente y con su sola presencia consigue dominar la situación en una secuencia magistral. Sofocada la revuelta, y con un delito de sedición a sus espaldas, don Saturnino es condenado a muerte con toda justicia por el héroe. Mas la idea seguía repugnando a Juan Martín, que le conmuta la pena por cincuenta palos, sin que en esta ocasión quede la menor duda de que actúa movido por la generosidad y nunca por miedo. Incluso le ofrece la posibilidad de permanecer en la partida con tal de que le dé una satisfacción pública por su insubordinación.

Con esta segunda versión el Empecinado se asienta como una figura noble, cauta en su conducta y generosa; en tanto que Albuin se degrada definitivamente sumando una vileza a otra: el robo y la traición. También en esta segunda versión queda resaltado el ambiente sórdido que dominaba en las partidas de guerrilleros, carcomidas por la más absoluta indisciplina y respetando sólo la ley del más fuerte.

El objetivo de la reelaboración hay que buscarlo en el afán de Galdós por marcar distancias entre el comportamiento de una y otra figura histórica. La conducta arrebatada de Juan Martín en la primera versión mermaba su grandeza heroica y lo situaba al nivel de un jefe cualquiera, iracundo y visceral. Del texto definitivo emerge un carácter muy distinto, enérgico con los insubordinados, capaz de imponer autoridad con su sola presencia, pero también magnánimo y generoso hasta unos extremos que sus enemigos son incapaces de comprender. La reescritura de esta secuencia no es sino una confirmación del título del episodio. Es notoria la voluntad del novelista de enaltecer a su héroe por encima de la canalla que se adscribía a las partidas.

No obstante, no debemos confundir este planteamiento con un intento, por parte del escritor, de crear una figura de epopeya. El Empecinado es 
presentado en su calidad de ser humano, con flaquezas y debilidades que pueden acarrearle consecuencias desastrosas. La imagen humanizada del héroe se filtra a través de escenas que lo describen ocupado en tareas cotidianas. En el cap. VI (pp. 42-45) asistimos a las dificultades del personaje para dictar un parte de guerra en el cual pretende dar cuenta de la acción de Calatayud. La p. 100 (cap. XIV) lo describe afeitándose con pulso vacilante.

Con todo, la noticia de la doble traición de don Saturnino y de Trijueque le hace perder el juicio y arriesgar la suerte de la partida en una aventura que casi le cuesta la vida a la totalidad de sus hombres y a él mismo. El texto primitivo también había previsto la narración de la emboscada que los renegados, en connivencia con las tropas francesas, tienden a «la gente empecinada». No obstante, ésta es una de las dos secuencias que en Alpha aparecen escuetamente referidas con unas pocas palabras clave, en espera de lograr un desarrollo definitivo en las' cuartillas de Beta. Es muy probable que el novelista estimase necesario recurrir a la ayuda de sus fuentes historiográficas antes de narrar un suceso que fue verídico. Por eso prefirió dejarlo indicado en las cuartillas desechadas, hasta haberse documentado debidamente ${ }^{14}$. Sea como fuere, el resultado de la emboscada es el mismo en una y otra versión: «el Empecinado» salva la vida in extremis arrojándose por un barranco y la mayoría de sus hombres son muertos o caen prisioneros. Entre los últimos se encuentran Gabriel y el pequeño Empecinadillo.

(VARIANTe 2) Son los capítulos XIV-XV-XVI-XVII (pp. 99-115), f. $<221>/ 231 /$-f. 222d-f. 223d-f. 224d-f. 225d-*f. 226d-f. 227d-*f. 228d y f. 229d: han sido reescritos en los actuales f. 232 al f. 274 , ambos inclusive. La diferencia tan considerable entre el número de cuartillas empleadas en la primera redacción y las que precisa la segunda se debe, como acabo de señalar, a que la segunda versión desarrolla completas dos esce-

14 El CONDE DE TORENO, Historia del levantamiento, guerra y revolución de España, Madrid, Biblioteca de Autores Españoles, t. LXIV, 1916, escribe:

Tuvo D. Juan Martín «el Empecinado» que deplorar en 7 de Febrero [de 1812] la pérdida de 1.200 hombres, acaecida en Rebollar de Sigüenza en un reencuentro con el general Guy, estando para ser cogido el mismo «Empecinado» en persona, quien sólo se salvó echándose a rodar por un despeñadero abajo. Achacaron algunos tal descalabro a una alevosía de su segundo D. Saturnino Albuin, llamado el Manco; y parece que con razón, si se atiende a que hecho prisionero éste tomó partido por los enemigos, empañando el brillo de su anterior conducta. Ni aun aquí paró el Manco en su desbocada carrera; preparóse a querer seducir a D. Juan Martín y a otros compañeros, aunque en balde, y a levantar partidas que apellidaron de contra-Empecinados, las cuales no se portaron a sabor del enemigo, pasándose los soldados a nuestro bando luego que se les abría ocasión. (Libro XIX, p. 401b)

Una vez más, ésta es, sin duda, la fuente historiográfica consultada por el novelista. 
nas muy importantes que en la primera redacción Galdós había resuelto con una simple indicación esquemática. Me refiero a toda la secuencia en la que la partida del Empecinado perece a manos de las fuerzas combinadas de traidores y franceses (f. 223d: «Batalla ---- nevada ---- Desastre --- caigo prisionero») y a buena parte de la escena de Araceli en el calabozo con el soldado francés (f. $227 \mathrm{~d}$ : «dialogo tierno con el frances ==»).

Por lo que respecta al texto que en términos generales mantienen en común las dos versiones, conviene apuntar que, el niño de dos años y medio, recogido en un pueblo arrasado por los franceses y que carga Santurrias, aparece ya en la versión primitiva. El chiquillo es encerrado con Araceli en la buhardilla de Rebollar de Sigüenza, donde comparte con nuestro narrador los instantes previos a su fusilamiento. El simbolismo del niño y su funcionalidad narrativa venían ya esbozadas en Alpha. En las últimas cuartillas escritas para la primera redacción hace acto de presencia el soldado francés Plobertín y, aunque el escritor ha solventado provisionalmente la escena con una escueta indicación: «dialogo tierno con el frances» (f. 227d), es previsible suponer que don Benito ya había esbozado mentalmente la funcionalidad de este diminuto personaje y el tipo de vínculo que se iba a establecer entre el chiquillo, Plobertín y Gabriel. Conviene, sin embargo, anotar que será ya en cuartillas compuestas ex novo para Beta en las que la criatura se convertirá en el artífice de la huida de Araceli en un doble sentido. Entre sus juguetes encontrará el narrador un trozo de lima robado por el niño al cerrajero de la partida con el cual podrá cortar los barrotes de la ventana (cap. XXII, pp. 145-146) y, finalmente, utilizará al niño como moneda de cambio para comprar su libertad (cap. XXIII, pp. 150-153).

Además, la figura del Empecinadillo facilita el vínculo entre la Historia y la Novela que debe estar presente en todo Episodio nacional. En la versión Alpha el novelista no se había dado un respiro para subrayar la importancia de atender con igual interés a la Historia grande que a los sucesos menudos, porque todos guardan entre sí relación en el conjunto del universo. En los folios de Beta (cap. XIV, p. 100) Galdós hace profesión de fe de esta creencia que sustenta todo el artificio de su novelística.

En lo que respecta a las novedades que ofrece la redacción definitiva, sin duda es un acierto que Galdós repetirá en Episodios posteriores el presentar a nuestro héroe ocupado en una acción tan cotidiana como la de afeitarse. Una tarea intrascendente es instrumentalizada en la narración para evidenciar la terrible agitación que en esos momentos domina el ánimo de don Juan Martín y que ya le acompañará hasta el final de la secuencia, siendo en buena medida responsable del desastre final de la partida de empecinados.

Además del vértigo con que está narrado el choque bélico, cabe destacar la atinada descripción de esa naturaleza gélida, aletargada por la que 
discurre un cuerpo de ejército abrumado con la idea de la traición de sus propios compañeros. El espacio exterior refleja la angustia interior de los guerrilleros. La tierra que pisan y sus propios pechos están igualmente helados. El otro aspecto destacable es el énfasis del novelista por denotar que en esta ocasión el Empecinado sí ha perdido por completo la serenidad de juicio. Es tal la humillación que le provoca la defección de sus mismos jefes que, desatendiendo toda clase de advertencias del juicioso Sardina, sale enajenado a buscarlos con la firme resolución de cazarlos o de dejarse atrapar por ellos. En el combate el Empecinado se conduce en todo momento como un exaltado, no atiende a razones, no procura la salvación de la partida $\mathrm{y}$, en contra de lo que era la práctica habitual de las guerrillas, se niega a aceptar la retirada como la táctica más acertada. En los últimos momentos leemos que es don Vicente Sardina quien trata de reagrupar a sus hombres y quien, llevándolo arrastras, consigue salvar la vida de don Juan Martín.

En cuanto a la trama argumental exclusiva del noveno episodio, no es mucho lo que queda por relatar cuando se interrumpe la composición de Alpha. En el texto definitivo, después de la lamentable acción en la que casi perece toda la partida, tenemos noticias de que don Vicente Sardina y el propio Empecinado se afanan por reunir a sus hombres (cap. XXIV, p. 154 , p. 158; cap. XXVI, p. 165), vuelven a atacar a los franceses (cap. XXVII, pp. 172-174), capturan a Trijueque y, en una especie de juicio sumarísimo, Juan Martín lo expulsa de la partida y lo condena a volver a Botorrita, el pueblo de donde salió (cap. XXIX, pp. 180-184). De esta manera, durante la redacción de la versión Beta, el novelista puede centrar su talento creativo en fraguar la trama folletinesca que presta unidad al conjunto de la serie.

Ya resulta sumamente significativo que la redacción primitiva haga crisis justo en el momento en que Santorcaz penetra en el aposento donde está prisionero Araceli (cap. XVII, pp. 114-115). A lo largo del cap. XVIII, y aprovechando que se encuentra ante un condenado a muerte, un don Luis enfermo relata a Gabriel las circunstancias que han hecho de él un hombre rencoroso y vengativo. Desde que en las páginas finales de La Corte... Lesbia contara a Máiquez algunos pormenores relativos a unos desgraciados amores juveniles de Amaranta ${ }^{15}$, el escritor ha venido desgranando el relato folletinesco de aquellos sucesos de una forma discontinua y casi, casi, improvisada.

Bien es cierto que, a estas alturas de la serie, el menos avispado de los lectores ha intuido ya lo que debió haber ocurrido. Sin embargo, lo cierto es que ningún personaje se había tomado la molestia de dar cumpli-

15 Benito PÉrez Galdós, La Corte de Carlos IV, Madrid, Alianza, 1986, cap. XXIII, p. 171. 
da relación de aquellos sucesos. En el noveno episodio de una serie prevista en diez entregas Galdós estima que ha llegado el momento de aclarar definitivamente la cuestión. Es ahora cuando tiene que detenerse un momento para acabar de urdir este aspecto crucialísimo de su narración, porque también está próximo el momento en que podrá demostrar que la nueva coyuntura suscitada por la guerra va a hacer factible para Gabriel lo que resultó imposible para Santorcaz unos años atrás: que un muchacho humilde contraiga matrimonio con una dama de alcurnia.

Don Luis relata a Araceli los términos precisos en los que se desarrolló su relación con Amaranta casi veinte años atrás. Santorcaz sitúa el principio y el final de aquellos amores en el castillo de Cifuentes y esto va a obligar al novelista a efectuar algunas correcciones sobre las cuartillas previas de Alpha. Así, ha incorporado un inciso (f. $31 / 2$, p. 8) en el que nos cuenta que Amaranta e Inés, tras desembarcar en Alicante, van camino de Madrid, donde piensan instalarse, si las circunstancias no las empujan a retirarse al castillo de Cifuentes, propiedad de la familia. También se ha visto obligado a reescribir un folio (el actual f. 201, p. 87, ha sido reescrito sobre la base del antiguo f. $<190>/ 201 /$ d) para modificar la posesión de dicho castillo, el cual en Alpha pertenecía al abuelo del difunto esposo de Amaranta, mientras que en la segunda redacción es presentado como posesión del dominio señoril de la familia de Leiva.

La segunda mitad del texto de «El Empecinado» da cabida a la preocupación de Gabriel por el bienestar de la condesa y de su hija. Juntamente con la relación de sus amores con Amaranta, Santorcaz le ha confesado al muchacho su propósito de raptar a Inés; y todos los afanes de Araceli se cifrarán en impedir esta violencia. Con este objetivo se escapa de su prisión y vive una serie de peripecias hasta llegar, irremediablemente tarde, al lado de la condesa. Así pues, la intención de don Luis de secuestrar a su hija no se hace explícita hasta Beta. En la primera redacción el novelista había andado demasiado atareado relatando las andanzas de los hombres de la partida como para prestar atención a los problemas sentimentales de sus personajes. Sólo una vez que ha fraguado definitivamente la trama particular del noveno episodio, procurará completar el tejido argumental de su novela atendiendo debidamente a la narración folletinesca.

Toda la primera serie se convierte en el cursus honorum particular de Gabriel Araceli y el logro de este episodio concreto se cifra en conseguir de Amaranta la promesa de entregarle la mano de su hija Inés si consigue arrancársela a su captor (cap. XXVIII, pp. 176-177). Para corresponder a este pacto sagrado la condesa, a partir de este instante, llamará al muchacho «hijo mío» (cap. XXVIII, p. 175, p. 176, p. 177 y p. 178). El apelativo no es mera expresión afectiva, explicita el nuevo vínculo que se establece entre los dos personajes y manifiesta la progresión social y personal de Gabriel. Progresión que, no hemos de olvidarlo, se mide siempre 
en función de su relación con la condesa. Gabriel empezó la serie sirviéndole de paje en El Escorial ${ }^{16}$ y la concluirá convertido en general y en su yerno ${ }^{17}$.

Galdós ha pautado milimétricamente los sucesos. La nueva actitud democratizadora de Amaranta coincide con el derrumbamiento del castillo señorial, que se ha venido abajo justo en el momento en que entraban las tropas francesas (cap. XII, p. 90). Esta circunstancia resulta simbólica en la semiótica particular del relato. La invasión napoleónica, en términos generales, supuso en España la caída del Antiguo Régimen. La nobleza pierde su razón de ser, el pueblo cobra protagonismo en la defensa de la nación y se advierte el ascenso de algunos individuos en una sociedad que necesariamente la guerra ha hecho más permeable ${ }^{18}$. La progresión social de Araceli está muy atinadamente ubicada en la cronología histórica española. Resulta curioso constatar que, para resaltar mejor el contraste con la actitud última de la condesa, Galdós, en la fase de pruebas corregidas ${ }^{19}$, ha incorporado varias adiciones en las que Amaranta, insistentemente, evocaba las glorias venidas a menos de sus antepasados (cap. XII):

nos asomamos a la ventana ojival de mi castillo (p. 88)

Los señores, mis antepasados que yacen aquí en sus góticos sepulcros, deben estar muy asustados y temerosos de que alguien remueva sus huesos. (p. 89) El lugar más seguro de la casa es el panteón, y en él vivimos todos, mano a mano con las tumbas de mis mayores. (p. 91)

Por último, quisiera detener un momento mi atención en la figura de mosén Antón Trijueque. Este personaje estaba ya previsto tal cual lo conocemos hoy en el texto primitivo. Salvo una breve variante al comienzo del relato con la que se prentende intensificar su responsabilidad en el apuro sufrido por Juan Martín ante los lanceros polacos de Alfamén (cap. IX, pp. 66-67), no se registan cambios relativos a esta figura en la redacción del episodio. Su descripción física y sus andanzas están ya previstas en Alpha y pasan sin alteración a Beta. Es cierto que la primera versión se interrumpe mucho antes de que llegue a plantearse su ahorcamiento (cap. XXX, p. 188). No obstante, sí está en esa primera redacción la traición de Trijueque (cap. XIII, pp. 92-98), y, al entrar en Sacedón (cap. I,

\footnotetext{
16 Benito PÉREZ Galdós, La Corte de Carlos IV, Madrid, Alianza, 1986, cap. XII, p. 90 .

17 Benito PÉREz Galdós, La batalla de los Arapiles, Madrid, Alianza, 1993, cap. XL, pp. 264-265.

18 Josep Fontana, La crisis del Antiguo Régimen 1808-1833, Barcelona, Editorial Crítica, 1983

19 Conviene hacer constar que no se han conservado las galeradas correspondientes a ninguno de los diez episodios de la primera serie. No obstante, resulta imprescindible reconstruir esta fase compositiva cotejando las diferencias existentes entre la última versión manuscrita y el texto impreso de la princeps y de otras ediciones posteriores.
} 
p. 9), lo primero que contempla el narrador son los cuerpos suspendidos de cinco franceses ahorcados. De esta manera, el relato adquiere estructura circular y no es mucho suponer que don Benito lo había planeado así desde el principio, por cuanto la imprecación característica de Trijueque es «iMe reviento en Judas!».

Mosén Antón es el gran personaje de esta novela. Su grandeza épica conmovía a Montesinos ${ }^{20}$. El novelista lo caracteriza como la encarnación del espíritu de las partidas, una figura netamente española. Y, sin embargo, me atrevo a asegurar que a través de él don Benito ha servido su crítica particular al emperador Bonaparte.

Hinterhäuser ${ }^{21}$ recriminó a Galdós no haberse atrevido a tratar más de cerca la imponente figura del militar del siglo. Esperando quizás una diatriva similar a la expuesta en La Fontana de Oro (cap. XLI) contra Fernando VII, el investigador concluye que no es mucho lo manifestado por nuestro escritor en su primera serie de Episodios. Por mi parte, entiendo que resulta admirable la sutileza con la que Galdós ha novelado su juicio sobre Napoleón a través del personaje de Trijueque, quien, en muchos aspectos, se convierte en un trasunto novelesco del referente histórico. Las diferencias entre ambas figuras, en apariencia insalvables, no lo son tanto, si analizamos el fondo de la cuestión. Don Vicente Sardina emite este juicio sobre el sacerdote:

\begin{abstract}
-Este clerigote es oro como militar; pero como hombre no vale una pieza de cobre. Parece mentira que Dios haya puesto en un alma cualidades tan eminentes y defectos tan enormes. No dudo en afirmar que es el primer estratégico del siglo. [...] Pero en mosén Antón la envidia es colosal, como todo lo de este hombre, cuerpo y alma. Su orgullo no es inferior a su envidia, y ambas pasiones igualan las inconmensurables dimensiones de su genio militar, tan grande como el de Bonaparte. (cap. IX, p. 63)
\end{abstract}

En Trafalgar $^{22}$ Gabriel confiesa ingenuamente que él se figuraba a Napoleón

igual en todo a los contrabandistas que, procedentes del campo de Gibraltar, se veían en el barrio de la Viña con harta frecuencia; me lo figuraba caballero en un potro jerezano, con su manta, polainas, sombrero de fieltro y el correspondiente trabuco. (cap. I, p. 9)

En el ms. de Gerona afirmará que no percibe ninguna diferencia entre el gran general y los más famosos bandoleros de Andalucía, Diego Co-

\footnotetext{
20 José Fernández Montesinos, Galdós, Valencia, Castalia, 1968-1969, vol. I, p. 99.

${ }_{21}$ Hans HINTERHÄUSER, Los «Episodios nacionales» de Benito Pérez Galdós, versión castellana de José Escobar, Madrid, Gredos, 1963.

22 Benito PÉREZ Galdós, Trafalgar, Madrid, Alianza, 1979.
} 
rrientes y José María «el Tempranillo», hecha excepción de su inmenso genio militar, que siempre le reconoce (f. 444) ${ }^{23}$.

Finalmente, en «El Empecinado» leemos:

Tres tipos ofrece el caudillaje en España, que son: el guerrillero, el contrabandista, el ladrón de caminos. El aspecto es el mismo; sólo el sentido moral les diferencia. (cap. V, p. 40)

Si Napoleón ha sido visto como un contrabandista y como un salteador de los caminos de Europa, también tiene algo de guerrillero. A mosén Antón se le reconoce sistemáticamente su inmenso genio militar, la única cualidad que Galdós descubría en Bonaparte ${ }^{24}$. Por otro lado, el cura de Botorrita tiene un defecto que será su perdición: la soberbia, el orgullo, la ambición. Exactamente igual que Napoleón, que caerá víctima del ansia desmedida de poder.

\section{APÉNDICE DOCUMENTAL}

\section{SIGNOS DE LECCIÓN EMPLEADOS EN LA TRANSCRIPCIÓN DEL MS.}

Las referencias iniciales de capítulo, página y folio: remiten al folio o folios del ms. y a la/s página/s de la edición de Alianza en las que se localiza la variante correspondiente.

El texto anotado en letra cursiva: enmarca el comienzo y el final de una variante estructural y proporciona las coordenadas, con respecto a la edición de Alianza, para localizar con total exactitud en el texto impreso definitivo la ubicación de la variante en cuestión.

$d$ : esta letra colocada detrás del número de un folio indica que esa cuartilla de un vuelto desechado.

${ }^{*} f$ : un asterisco delante de un folio señala que se trata es una supuesta cuartilla desechada no conservada.

$<>$ : encuadran estadios de redacción que aparecen tachados linealmente en el ms.

/ /: encuadran la versión última que ofrece el ms. después de una o varias tachaduras sucesivas. También indican las adiciones interlineadas.

$<\mathrm{xxx}>$ : tachadura muy gruesa imposible de descifrar.

$\langle\ldots\rangle$ : tachadura de trazo simple que no logro descrifrar.

\#\#\#: palabra no tachada que me resulta ilegible.

[ ]?: parte reconstruida hipotéticamente de una palabra escrita incompleta y tachada.

[ ]: folios desechados completos y amplios fragmentos desestimados en folios válidos mediante trazos oblicuos.

\footnotetext{
23 Guardado en la Biblioteca Nacional de Madrid con la signatura: Ms. 21. 751.

24 Joaquín CASAlduERo, Vida y obra de Galdós (1843-1920), Madrid, Gredos, 1974, p. 51 .
} 
| |: cada folio reescrito sobre la base de un folio o folios desechados conservados.

Los sangrados escritos entre corchetes [ ]: dan cabida a la explicación pormenorizada de todo el proceso de reescritura que ha tenido lugar en la variante correspondiente que es objeto de reconstrucción y transcripción.

La acentuación y la ortografía son las de Galdós.

VARIANTE 1: Cap. XI (p. 79-86), ff. 181 al 197: Hoy mi jefe no tiene confianza en mí. Bueno, yo le digo que me mande fusilar al

[ f. 181d: instante, porque no me da la gana de darle el dinero que me pide y que efectivamente tengo.

-Volvemos á la bromita de mosen Anton? /-dijo D. Juan.-/ No me lo digan mucho, porque ya me van cargando los valentones, y aunque me quede sin heroes en la partida, haré <un dia> un escarmiento.

-Pues yo digo que hasta aqui llego $<$ la ...> la paciencia -afirmó Albuin poniéndose livido- y de aqui no ha de pasar. <D. Juan Martin> El que quiera el dinero, lo recogerá de mi cadaver.

En <un> /un/ juramento horrible, D. Saturnino retó á Cielo y <xxx> tierra.

-Pues sea, -dijo <D. Juan Martin>/el Empecinado/ poniéndose en pié.- S. D. Vicente Sardina, mande Vd. fusilar inmediatamente al primer soldado de la partida, D. Saturnino Albuin.

El generoso corazon del Empecinado no dejaba de ]

[ f. 182d: enaltecer las altas prendas militares de sus subalternos, ni aun al hacer recaer $<$ sobre el $>$ sobre ellos la pesada $</ y$ cortante/ $>$ cuchilla de la rigurosa ordenanza. Por lo demas, Albuin al expresar $<\mathrm{xxx}>$ su ultima y <de> al parecer decisiva resolucion, creia firmemente que D. Juan Martin no se privaria de tan buen <...> soldado por una cuestion que estimaba baladi, y tambien tenia la seguridad de que <las >/parte de las/ tropas se insurreccionarian ante <la $>$ el cruel castigo impuesto á uno de los gefes mas <queridos> /queridos./ No <xxx> tuvo valor esta consideracion en el animo del general, que se empeño en llevar adelante el propósito <de $>$ formulado por su ardiente corage; mas D. Vicente Sardina que <xxx> á sangre fria calculó las consecuencias de paso tan peligroso, quiso dar sesgo distinto á la cuestion, en provecho del ejército, de la disciplina y del decoro de los gefes.

- Las cosas no irán tan allá -dijo-D. Satur- ]

[ f. 183d: nino entregará el dinero, sin perjuicio de que despues se le $<\mathrm{xxx}>$ den las pagas... Es justo.

$-<\ldots>$ Vamos á la plaza - dijo resueltamente el Manco- <Veremos> /Fórmese el cuadro, y veremos/ si hay un soldado que dispare sobre el pecho de D. Saturnino Albuin.

El Empecinado, encendido en ira, rabioso, exaltado, fuera de si, vociferó de este modo <perdiendo >: 
-Pues si no hacen fuego sobre el pecho de Albuin, lo haran sobre el del Empecinado. Moriré atravesado por las balas de <los mios $>/ \mathrm{mis}$ queridos muchachos/, antes que consentir <que se me ultraje> faltas tan garrafales de disciplina... No digo mas... Cúmplase.

Metiéndose las manos en los <...> bolsillos, hundió la barba en el cuello del capote y se paseó de un rincon á otro <xxx> en la <habitacion> /estancia./

-Vamos, - dijo el Manco.- Señor Sardina disponga Vd. de mi, estoy pronto.

-Alto ahi, - grito de subito el Empecinado, deteniéndose y ]

[ f. 184d: dando <una> / tan/ fuerte patada en el suelo que hizo retemblar el piso y la casa entera.- Alto ahi ?á que tanta prisa?

- Cuando le han de quitar á uno la vida, - dijo Albuin.- cuanto mas pronto mejor.

-Y si á mi me da la gana de indultarle á Vd.? Vamos á ver. -exclamó el <Em[pecinado]?> /general/- Si á mi me da la gana de mandar que le den cincuenta palos, cogerle despues por una oreja y ponerle al frente de su division con pena de no darle sus pagas hasta que no tome á Borja y me traiga la guarnicion francesa?... Vamos á ver, si yo dispongo esto... <que> /quél tiene Vd. que chistar?

-Albuin, - dijo D. Vicente, aprovechando aquella buena disposicion del gefe- obedezca Vd. á nuestro general; entréguele lo que le pide, y todo concluirá en bien; <que>/pues/ es lastima que por una bicoca de $<\mathrm{xxx}>$ doscientos ó trescientos cochinos pesos duros <perdamos <á uno de los $>$ al pr[imero]?>/tengamos aqui un disgusto./ ]

[ f. 185d: -Esto se acabó, - dijo lugubremente D. Saturnino.- < Juan Martin> <libreme Dios de los amigos que mandan ...> Si el general sale ahora con la pamema de indultarme, no se lo agradezco. $<$ De buena ga[na]?> No es piedad lo que siente por mi sino miedo. A un hombre como yo no se le fusila. Juan Martin, -añadió <metiendo la mano util en> llevando la mano util á la cintura y desliando un cinto de seda $<\mathrm{xxx}>$ que arrojó /á larga distancia/ sobre la mesa,- - ahi tiene Vd. su dinero. No se sofoque vuecencia por tan poca cosa. D. Saturnino Albuin es un hombre honrado y generoso que sabe sacrificarse por los amigos. Pobre y desnudo vine á la partida; pobre y desnudo salgo de ella. Adios señores. El Manco no puede seguir ni un momento mas en este ejercito, porque al Manco se lo ha faltado, al Manco se le trata como si fuera un perro... Otras partidas y otros generales hay en España que quizas encuentren algun mérito en este pobre invalido, y le agazajen y le mimen... Muchos amigos tengo en esta <patid[a]? > /partida/: de todos $<$ modos $>$ me despido con verda- ]

[ f. 186d: dera afliccion $\longrightarrow$ (al decir esto el Manco mostraba en su voz cierto enternecimiento, verdadero ó fingido) á todos les pido perdon si les he ofendido alguna vez y me voy, si señores, me voy, porque ya no puedo aguantar mas. 
El Manco se arrojo en brazos de Sardina. D. Juan Martin mirábale de hito en hito sin <decirle>/decir/ nada.

$-<$ Voy $>$ Con dios, señores, - añadió <el> D. Saturnino sacando los bolsillos y mostrandolos vacios. - Vean que no me llevo nada... Señor D. Juan Martin. Acabose para V. el Manco, y Vd. acabó tambien para el $<\mathrm{M}$ [anco]? > <pobre> Manco. Grandes hazañas hemos realizado juntos. <La historia> La gente de Madrid primero y la historia despues pondran por las nubes al Empecinado; pero nadie se acordará del pobre Manco. No me importa. Yo le regalo á Vd. toda mi gloria... Hemos sido amigos. Ya no quiero mas amistades. Yo me basto y me sobro. A los hombres como yo no se les tira de las orejas. ]

I f. 181: instante, porque no me da la gana de darle el dinero que me pide y que efectivamente tengo.

-Volvemos á la bromita de mosen Anton, -dijo D. Juan Martin.No me lo digan mucho, porque ya me van cargando los valentones; y aunque me quede $\sin <$ hero[es]?>/heroes/ en la partida, haré un escarmiento.

-Pues yo digo que hasta aqui llegó la paciencia - afirmó Albuin poniéndose livido y retando con la $\langle\ldots . .>$ mirada al general.- No aguanto mas; no doy dinero, ni sirvo mas en la partida. <Ea...> /Ea.../

Levantose de su asiento D. Juan Martin <rompi[endo]?> /como si una esplosion le sacudiera, rompiendo/ el sillon, /y/ volcando la mesa $<y>$.

-Pues tambien se me acabó la paciencia! -exclamó con furia.- Usted aguantará, Vd. dará el dinero, y Vd. no saldrá de la partida.

-Veamos como ha de ser eso, no queriendo yo, - dijo ।

I f. 182: el Manco, poniéndose en la <...> actitud <...> del carnivoro que espera ataque de <una> fiera mas poderosa.

- Albuin, Albuin! - grito con tremendo alarido D. Juan dando tan fuerte patada, que piso, paredes techo y todo el edificio se estremecieron.- Es la primera ver que un <hombre>/subalterno/ se revuelve contra mi de esa manera; y no lo pasaré, no lo pasaré.

$<\mathrm{El}>$ /El/ Manco entonces llevose la derecha mano precipitadamente al cinto, y exhaló un rugido de desesperacion. No tenia sable. Se lo habia quitado antes de comer, arrojándolo en un rincon.

$-<$ Te hace $f[$ alta]? $>$ Le hace falta a V. un sable, ahi va el mio, -dijo D. Juan Martin, arrojando el acero desnudo ante los piés de $<$ Albuin> /el guerrillero./- Defiendase V. porque le voy á amarrar los brazos con esta cuerda para llevarle <al sotano de>/preso al sótano de/ esta casa. I

If. 183:<No> <Estamos no> Estabamos todos los presentes mudos y aterrados y no nos atrevimos á intervenir en la dramatica escena. Con presteza suma D. Juan tomo una soga que cerca habia y se dirigió hacia su subalterno, diciendo:

-Dese V. preso, señor deslenguado. Estoy cansado de ser bueno.

El Manco haciéndose atras, exclamó:

-No necesito cuerda. Me dejaré matar antes que consentir que me aten como á un ladron... Adonde tengo que ir? Al sotano? No me da la 
gana. Señor general -añadio, recogiendo el <sable> /arma/ del suelotome V. su sable y atravieseme con el, porque Albuin no se deja atar la <única> mano que le queda... Iré preso: que me fusilen al instante, y entonces <tomaran el dinero>/si quieren <el>/mi/ dinero, lo recogeran/ de un cadaver.

$<x x x>$ No pudo seguir, porque con <la rapidez del $>$ una rapidez, una seguridad, una destreza extraordinarias, la ma- I

I f. 184: no poderosa de D. Juan Martin asió con <...> el vigor de $<$ una $>$ /ferrea/ tenaza la estremidad derecha del Manco, el cual bruscamente cogido, forcejeó, se $\langle\ldots\rangle$ doblegó, dió un terrible grito, agitando el <muñon> impotente muñon de su <extremid[ad]?> /extremidad/ izquierda.

-De rodillas, - vocifero el general, sacudiendo con su membrudo brazo aquel cuerpo de acero que se cimbreaba como una hoja toledana.De rodillas delante del Empecinado.

$<$ El $>$ D. Saturnino, una vez presa lá mano derecha, era hombre perdido, una espada sin punta, una culebra $<\sin >/ \sin /$ veneno. Su muñon hizo esfuerzos formidables pero no pudo defenderse. Al fin despues de repetidos arqueos $<\mathrm{y}>/ \mathrm{y} /$ dobleces, las agudas rodillas del heroe, cayendo con violencia, hicieron estremecer el suelo. Se oia un resoplido <de> /de/ animal vencido.

-Miserable ladron, _exclamó el Empecinado <...>

I f. 185: con voz <tambien> indecisa y ronca á causa del gran esfuerzo- Ahora mismo me entregarás lo que te pido, ó $\langle\ldots\rangle$ pereces á mis manos.

En el mismo <m> instante, <vimos ...> observamos que la cabeza de D. Saturnino hizo vivísimo movimiento; <vimos relucir sus> y sus blancos dientes se clavaron en la mano potente que el sugetaba.

- Me muerde este perro, - exclamó D. Juan Martin con súbito dolor.

Forcegeó segunda vez el Manco y pudiendo al fin desasirse, <corrio á la inmed[iata]?> <como> /corrio de un salto á la inmediata/ ventana. Abriendola grito hacia afuera:

—Soldados, muchachos, amigos!... a mi! á mi... Socorro! Quieren asesinar á vuestro querido Manco... Arriba todo el mundo.

$\mathrm{Y}$ dicho esto, volviose hacia dentro y <nos> miró á su gefe y á todos con espresion de salvage alegria. I

I f. 186: D. Juan Martin, cuya mano sangraba, recogió su sable. Todos nos apercibimos, barruntando algo grave, porque D. Saturnino, ademas de ser muy querido de sus tropas, tenia una especie de $<\ldots>$ guardia negra, compuesta de los mas salvages, feroces, y barbaros hombres de aquel ejército.

-Esto es una infamia! - gritó Sardina- Concitar á las tropas á la insubordinacion.

Albuin seguia gritando: -A mi, muchachos! Subid pronto.

Oyose rumor <muy>/muy/ imponente en la vecina escalera. 
-Cerremos las puertas, - dijo Sardina, disponiéndose á hacerloTiempo <habrá> /habrá/ de hacer entrar en razon á esa canalla. trar!

-No; -gritó con furia el general esgrimiendo el sable- dejarles en-

No <tardó en aparecer la p[artida]?> tardaron en aparecer algunos que eran la hez mas abominable de la partida. Algunos hombres rudos, negros, I

I f. 187: sucios, de mirada aviesa y continente repulsivo <...> se presentaron en la puerta.

-Que hay? - preguntó el general, mirándoles con terribles ojos.Que buscan Vds.

-Aqui estamos, señor Manco, -dijo uno resueltamente entrando.

<Todos> Aquel y los demas que eran hasta veinte ó veinte y cinco dieron algunos pasos dentro de la sala.

-Atras, atras todo el mundo, - gritó resueltamente el Empecinado, $<\ldots>$ adelantandose hacia ellos con la magestad del heroismo.

-Dejareis que asesinen á vuestro querido Manco - exclamó en el <...> hueco de la ventana, la voz angustiosa de D. Saturnino

- <Aqui no ...> Mando que se retiren todos, - repitió D. Juan Martin, ó les mando fusilar á todos. <Al que me> /Soy el general I

I f. 188: ... Al que me/ desobedezca, le tiendo aqui mismo... Ea... den un paso si se atreven!... que vengan mas... Aqui espero... Que venga todo <un ej[ército]?> /mi ejercito/ á <asesinar á> /atropellar á/ su general... Aqui me teneis, cobardes... Venid... que venga mas gente... Somos cuatro... Matadnos... pisad el cadaver de $\langle\ldots\rangle$ vuestro general.

Una voz horrible clamó en la escalera

-Viva D. Saturnino el Manco!

$<$ Uno> Dos de los que habian entrado, adelantaronse lanzando <xxx> votos y juramentos, hacia D. Juan Martin. Pero este con <vigor> empuge vigoroso descargó sobre la cabeza de uno de ellos tan fuerte sablazo, que $<\ldots>$ le abrió á cercen la cabeza.

El soldado cayó <muerto al suelo> /al suelo muerto/.

$<$ Dió algunos pasos hacia $>$ Arrojamonos los otros tres en auxilio del general y esgrimimos los sables con- I

I f. 189: tra aquella infame canalla. Aunque acobardados y aterrados por la presencia, por la voz, por <la > el heroismo sublime de D. Juan Martin, trataron de defenderse, fiados en su gran número; pero no tardamos en hacer estrago en ellos. Dispararon ellos algunos fusilazos, que por fortuna <solo $>$ no $<$ nos $>/$ nos/ hicieron otro [d]año que una herida leve recibida por mi y otra que le cupo en suerte á Sardina; mas acometidos bravamente, huyeron por la escalera abajo

D. Juan Martin, bajó repartiendo sablazos á diestra y siniestra, y nosotros tras él. Otras tropas invadieron el edificio, y la chusma partidaria del Manco, perdiose entre la multitud afecta al generoso gefe. 
- Crudo, -exclamó este- Es preciso fusilar ahora mismo á toda esa canalla. Sardina: dé V. las ordenes <con[venientes]?>/necesarias./ Quintarlos es mejor... Asegurarles I

I f. 190: bien... El tuerto es el peor de todos... Esos tres, esos tres que se <escabull[en]?> /escabullen/ por ahi tambien subieron... Que no se escapen. Ponerles en fila... yo les reconoceré... Eh! Moscaverde... al instante, es preciso castigar esta gran $<\mathrm{xxx}>$ alevosia.

<Los sol[dados]?> La tropa gritó:

-Viva el /gran/ Empecinado!

- Gracias, gracias, - dijo el heroe.- Dejarse de vivas y portarse bien... Voy á hacer un escarmiento esta noche... Hace tiempo que lo estoy meditando, y en verdad es necesario... Nadien se rie de mi.

Subimos de nuevo $<y>$. Ya en la sala del ayuntamiento habia bastante gente, y D. Saturnino era custodiado por $<$ fuerza $>$ /gente/ leal. El Empecinado al encarar nuevamente con él, le dijo:

- Señor Manco, dispongase Vd. para el requieternam. Aqui no hay mas capellan que mosen Anton y ese ha I

I f. 191: olvidado el oficio. Haga V. acto de contricion.

-Despachemos pronto, - dijo el Manco < xxx> esforzandose por aparecer sereno, pues aquel hombre, bravo cual ninguno en las batallas, carecia de valor moral- Despachemos pronto... Mande vuecencia formar el cuadro en la plaza... Pueden llevarme cuando quieran.

D. Vicente Sardina entró en la sala:

- <Ning[uno]? > Solo dos se han escapado, - dijo-. Les conozco bien. Ya estan dadas las órdenes. Se <diezm[arán]?> /quintarán./

<D.>-S. D. Sardina, - añadio el Empecinado.- El S. Albuin no sera arcabuceado por la espalda. Se le apuntará por el pecho, atencion á que ha sido el primer soldado de este ejercito.

El generoso corazon de D. Juan Martin no dejaba de enaltecer las prendas militares de sus amigos ni aun cuando hacia caer sobre ellos la pesada cuchilla de la ordenanza. I

I f. 192:Oyose <una detonacion> /el ruido de una descarga/. Reinó despues lugubre silencio en la sala, solo interrumpido por la voz de <Albuin, que elevando las manos al Cielo>/Sardina que dijo uno, la de Albuin que elevando sus manos al cielo,/ exclamó con dolorido acento: -Adios, amigos mios! adios. Valientes camaradas. Ya no venceremos á los franceses, ni nuestros generosos corazones volveran á <...> palpitar con el entusiasmo de la batalla.

<-Bueno será que este hombre se ...>

Despues echandose mano á la cintura, deslió la culebrilla de seda que en ella llevaba, y arrojandola en mitad de la sala, añadio:

-Ahi esta el dinero, Sr. D. Juan Martin, ahi estan esos trescientos cochinos pesos, que son causa de la carniceria que se esta haciendo abajo con mis bravos leones. Desnudo y pobre entré en la <...> partidal 
I f. 193: y pobre y desnudo salgo de ella para el otro mundo.

Oyose otra descarga, y D. Vicente, dijo:

-Dos. Cayó otra buena pieza.

- Puesto que voy á morir, - añadio D. Saturnino- que no maten mas gente. Yo fui causa de todo. Yo les mande subir.

- <Usted> A usted no le va ni le viene nada de esto - dijo D. Juan, no ya colerico sino displicente,- Usted hará lo que se disponga y nada mas.

Dicho esto, metiose las manos en los bolsillos, hundió la barba en el cuello del capote, y se paseó de un rincon á otro.

-Vamos, de una vez, - dijo el Manco.- Estoy dispuesto á morir. Al cuadro. ban. I

Dió algunos pasos hacia la salida, seguido por los que le custodia-

I f. 194: -Alto ahi, - gritó de súbito el Empecinado, golpeando el suelo, deteniendose en su marcha, $<\mathrm{y}>/ \mathrm{y} /$ mirando á la victima con rostro ceñuda.- Quien le manda á Vd. bajar antes de que yo lo disponga.

-Cuanto mas pronto mejor, - repuso la victima.

Oimos la tercera <det[onación]?>/descarga/ de fusileria.

-Quieto todo el mundo! — repitió <todo el mund[o]?> D. Juan.Aqui no manda nadien mas que yo.

-Quiero que me fusilen! -exclamó Albuin con corage, sacando á los ojos todo el odio de su corazon lleno <á ...> entonces de veneno.

-Y si $<\ldots>$ á mi me diera la gana de indultarle á V. /vamos á ver/ - exclamó el general $\langle\ldots\rangle$ con furia, como si la muerte fuera la condescendencia y el indulto la amenaza.- Vamos á ver: si á mi diera la gana de indultarle y mandar que le dieran cincuenta ।

I f. 195: palos por la mordida, y luego cogerle por una oreja, y ponerle al frente de su division, con pena de $\langle\ldots\rangle$ otros cincuenta garrotazos, si no me tomaba á Borja, trayendome acá prisionera media guarnicion francesa...?

-A un hombre como yo, no se le dan cincuenta palos, -repuso el Manco,- ni se le tira de las orejas.

-Todo será que á mi se me antoje... Que tiene Vd. que decir? Ea... soltadle, y fuera de aqui todo el mundo: Sr. Sardina, mande V. que no se fusile á nadie mas. Palos /y mas palos/... es lo mejor.

Marcharonse los de tropa y quedamos con D. Saturnino los cuatro que antes estábamos. dezca.

- Le perdono la vida, - dijo el general. Puede ser que no lo agra-

-No, - <dijo $>$ /repuso/ Albuin sin inmutarse.- No agradezco, porque parece generosidad y no lo es<?> ।

I f. 196: -Pues que es, que?

-Miedo, -añadió el guerrillero gravemente.- A un hombre como yo no se $\langle\ldots\rangle$ le pone dentro de un cuadro. La tropa no le consentiria... $<\ldots>$ y si lo de antes salió mal, otra vez... 
-Estoy por volverme atras de lo dicho, y mandar que se forme el cuadro... Pero no: <el Em[pecinado]?> cuando el Empecinado perdona... D. Saturnino, marchese V. y <no vuelva $>$ haga lo que quiera. Si desea seguir <al frente de su division> /en este ejecito/, deme una satisfacion enfrente del ejercito. Si no...

-D. Saturnino Albuin no da satisfacciones, -repuso este, - < Menos $>$ ni necesita mendigar un mando. Me voy. Adios para siempre <Juan $\mathrm{Ma}$ [rtín]?>/Juan Martin/ acabó para el Manco, y el Manco acabó para Juan Martin. Grandes hazañas hemos realizados juntos. I

I f. 197: La gente de Madrid primero y la historia despues, se harán lenguas al hablar del Empecinado; pero nadie se acordará del pobre Manco... Yo le regalo al general toda mi gloria... Señores, adios. D. Saturnino Albuin <vá á pedir limosna> /que no puede manejar la azada, ni el telar, va á los caminos á pedir limosna./ Dios tenga compasion de él. I

\section{XII}

Marchóse Albuin. Luego que salió advertimos en el general un desasosiego,

[Los antiguos f. $181 \mathrm{~d}$, f. $182 \mathrm{~d}$, f. $183 \mathrm{~d}$, f, $184 \mathrm{~d}$, f. $185 \mathrm{~d}$ y f. $186 \mathrm{~d}$ de Alpha han sido desechados y reescritos ampliadísimos en los actuales f. 181 al f. 197, ambos inclusive, de Beta. La sustitución de la primera redacción por la segunda se produjo en el momento de transformar Alpha en Beta, de ahí que, al tener que subsumir un número importante de nuevas cuartillas, Galdós se viera en la necesidad de incrementar la numeración de los folios inmeditamente siguientes a los reescritos, convirtiendo el antiguo f. $<187>$ en el actual f. $/ 198 /$ y así sucesivamente. Para la composición del f. 197 Galdós ha aprovechado menos de la mitad de la cuartilla y el texto concluye con un trazo ondulante sobre el resto del espacio, en blanco, indicativo de que el discurso narrativo continúa en el folio siguiente, es decir, el f. <187>/198/.]

VARIANTE 2: Caps. XIV-XV-XVI-XVII (pp. 99-115), ff. $<221>/ 231 /$ al 274: parche de los tambores, dando a estos instrumentos de guerra ronco y apagado sonido;

[ f. <221> /231/: quitaba <la paja á los caballos, metia las narices en ... ... de los cartuchos, <y cogia > /para coger/ puñados de polvora $>$ á los soldados los cartuchos y á todos la paciencia con sus diabluras sin fin. Recibia, si, mas azotes que un condenado á galeras; pero ]

[ f. 222d: como buen soldado, hecho <á> /á/ las penas y fatigas, no perdia $<\mathrm{xxx}>$ su alegria $<\mathrm{xxx}>$ con los castigos. 
Cuando encontramos á D. Juan Martin en Almadrones, y le dijimos lo que habia pasado, enfureciose y nos dijo:

-No puede ser. Mosen Anton tiene sus defectos; es capaz de acabar la paciencia á un santo con sus majaderias; pero antes me creeré á mi mismo traidor que suponerle vendido al enemigo.

- Pronto lo hemos de saber -dijo Sardina que no participaba de la confianza de su gefe y amigo.- Un hombre en su despecho es capaz de todo. Yo tenia á Trijueque por <un> ]

[ f. 223d: hombre discolo, intratable, <mas > /pero/ < de fondo > con un fondo de rectitud, superior á traiciones y villanias, como la de D. Saturnino. Sin embargo, nada me sorprende.

- Si fuera verdad, - dijo el general con rabia. - $<\mathrm{Si}>/ \mathrm{Si} /$ fuera verdad, y le cogiera, todo su pellejo me $<\mathrm{xxx}>$ pareceria poco para componer los tambores que ha roto el Empecinadillo.

Despues D. Juan Martin que estaba

Batalla -..- nevada -..- Desastre -..- caigo prisionero

Hallabame en <la> una habitacion alta, <ahumada,> de bajísimo techo abohardillado, sin mas comunicacion con el esterior que un pequeño ventanillo sin cristales, el cual se abria sobre un largo <xxx $>$ balcon <que > del piso principal. Mi <xxx> primer cuidado fué tapar con algo aquel hueco por donde el viento de la noche entraba á visitarme, y no hallando nada á propósito con que hacerlo sino me desprendia de mi <capote> /capote,/ bus- ]

[ f. 224d: que refugio contra el frio debajo <de la> del mismo tragaluz, sitio donde apenas llegaban sus bocanadas de hielo. El Empecinadillo <acurrucandose ...> despues que lloró durante dos horas, durmiose como un angel, hallando facil abrigo á mi lado. Yo no cerré los ojos en toda la noche. Sentia <xxx> las voces y patadas de los franceses que jugaban y bebian en el piso bajo, y los pasos del centinela que se paseaba en el balcon, como á <cuatr[o]?> /seis/ varas mas abajo del ventanillo.

Por la mañana, el chico se despertó pidiendo de comer y me fué forzoso <emplear> apurar todas las razones imaginables para convencerle, aunque vano, como es natural. Llorando y jimoteando pasó buena parte de la mañana, hasta que se sirvió visitarnos un francés, <xxx> que nos traia de comer.

- Preparate - me dijo-Vas á ser arcabuceado.

No le contesté, y di la comida al Empecinadillo.

-Que vas á ser arcabuceado por traidor, - repitio /cuadrándose ante mi./- No lo \}

[ f. $225 d$ : oyes? charse.

-Ya; no soy sordo, -le respondi- Haga/me/ V. el favor de mar-

- Arcabuceado - añadió <mirandome con> acompañando sus palabras de un gesto significativo.- No se $<\ldots>$ quieren prisioneros. Vues- 
tro camarada que esta en la otra bohardilla lo sabe ya tambien y se ha puesto á rezar. No rezais vos?... <Los > /Los/ que se convienen con nosotros para servir al Rey José, son perdonados... Yo no les perdonaria tampoco. Todos son unos pillos, y luego se vuelven á pasar á los españoles.

-Y hacen bien, -le respondi.

-Es preciso limpiar este pais de tunantes. <Es $>$-añadió <manifestando que tenia $>$ /mostrando/ deseos de conversacion- Es la opinion del Emperador y la mia. <El rey José es muy blando de corazon y quiere contemporizar.> Es el gran sistema. Por eso cuando tomamos á Dantzig...

—No quiero saber nada de eso... Fuera de aqui, - -le dije ]

\section{[*f. 226d]}

[ f. 227d: lágrima.

-Porque llora V.? -le pregunté

-Este muñeco <me re[cuerda]?> /-repuso,- me recuerda/ á mi pequeño Claudio, á quien deje en mi pueblo... yo soy de Maus la Tour, en los Vosgos... Ahora tendrá dos años y medio y debe estar lo mismo que este.

-Es V. casado?

- Si, - respondió, cogiendo al Empecinadillo en una de sus rápidas vueltas y besándole. - Soy casado, pero <como no tenia posibles y nos moriamos de hambre, senté plaza.> en la última conscripcion, el emperador echo mano de los casados... Es un dolor, <no > es una picardia, no se verdad?... Ahora que nadie nos oye... Separarle á uno de su muger y de su hijo, para enviarle á esta maldita guerra de España que no se acaba <nunca> /nunca.../ Mi pequeño Claudio no se me aparta de la memoria

$$
\text { dialogo tierno con el francés }==\text { ] }
$$

[*f. $228 d$ ]

[ f. 229d: -De todo hay, - repuso buscando <un asiento con la vista $>$ /con la vista un asiento/- No hay aqui donde sentarse. Nos sentaremos en el suelo. No puedo estar en pié. Padezco mucho.

-Esta Vd. enfermo.

- Si, - me dijo echandose en el suelo y oprimiéndose el pecho con $<$ la $>$ /una/ mano, mientras se apoyaba en el otro brazo. - <... He contraido una enfermedad en el corazon. Soy desgraciado, Gabriel. No se puede <vivir > /vivir/ con estas <xxx> serpientes en el <xxx> órgano principal de la <vida > /maquinaria humana.../ Conque <cuéntame <...> tu vida $>$ vamos á ver, joven. Ya nos conocemos de antiguo. A que andar con preambulos. Yo vengo aqui á solicitar de ti que te pases á nuestro campo. ] 
-Mal dicho -repuse con calma-, porque no lo haré. Acepto la muerte. Semejante

[Existió una secuencia primitiva de folios de Alpha que iba del antiguo f. 222 al antiguo f. 229 , ambos inclusive, que fue desechada y reelaborada de un modo genérico en los actuales f. 232 al f. 274, ambos inclusive, de Beta. De la secuencia tachada se han conservado los siguientes folios: f. $222 \mathrm{~d}$, f. $223 \mathrm{~d}$, f. 224 d, f. 225 d, f. 227 d y f. 229 d. El f. 229 d no ha sido escrito completo. Para su redacción, que Galdós sentía como provisional, puesto que a partir de él se detiene la composición lineal del episodio y se procede a una fase de revisión y reescritura de lo ya elaborado, el novelista aprovechó las dos terceras partes de la cuartilla. La sustitución de la primera redacción por la segunda se produjo en el momento de transformar Alpha en Beta. De ahí que no haya discontinuidades en la reenumeración final.] 